\title{
Formation of Food Clusters in Europe
}

\author{
Márta Völgyiné Nadabán \\ INNOVA Észak-alföld Regional Development and Innovation Agency Nonprofit Ltd., Debrecen \\ pvolgyi@gmail.com
}

Keywords: Enterprises, food industry, business clusters

\section{SUMMARY}

In the dictionary of foreign words and phrases we can find the word "cluster" with the following sense: aggregation, group and in a wider meaning: association, integration.

By explaining the geographical concentration of economical and innovation processes in the food processing sector, clusters, and especially business clusters, play an important role. This essay deals exclusively with business clusters, so the term cluster is used also for business cluster.

I tried to collect the most relevant indicators determining the formation of clusters in the Food Processing Sectors and to analyze whether a correlation can be found among the analyzed indicators.

\section{MAIN CHARACTERISTICS OF BUSINESS CLUSTERS}

The concept of clusters is a modern definition of the geographical concentration of economic activities as important factor of economic development. Marshall (Marshall 1890) monitored the concentration of workforce and specialization already in the 19th century from the point of view of economic activities.

The definition of clusters can be determined from different perspectives and these definitions have been shaped from time to time. The most well known concept originates from Michel Porter. He drafted the so-called "diamond model" of competitive advantage (Porter 1990). He viewed the concentration of economic activities in clusters as a result of "competitive advantages" of firms in finding new and improved ways to compete in an industry and to bring innovation faster to the market (Regional clusters in Europe, 2002).

\subsection{Overall characteristics of clusters}

The different concepts of clusters have some common factors as follows:

- Clusters are geographical concentrations of specialized firms, supporting institutions and competent labor forces.

- The foundation of clusters serve from functional point of view the need for specialized and customized services to a specific group of firms, such as the provision of advanced infrastructure, specific business support services.

- Clusters are determined by a certain social and organizational element that connects the different innovation actors (universities, companies and public authorities) and facilitate them for more intense interaction and cooperation.

The clusters can be determined by the connections established in the cluster and not through the members: the geographical borders of a cluster are mostly not equal to the political borders. The business clusters are mostly not related to only one specific field they cover more sectors by creating a new business.

\subsection{Emergence of clusters}

The emergence of a cluster in a particular field can be explained in various ways:

- The first approach builds on factor advantages, such as natural resources, transport routs, climates, which are the basic requirement for production.

- The second approach builds on "accidents", such as the attendance of a successful entrepreneur, research institute.

\section{FORMATION OF FOOD CLUSTERS}

\subsection{Statistical background}

Based on the above mentioned theoretical introduction, it is clear to see that it is a basic requirement to have a solid background for analyzing the geographical concentration of enterprises and related actors like universities, research institutes and intermediaries on the field of food industry. The Eurostat database collects some information on this particular field but only some of them are suitable for a deeper analysis. I collected 
several possible indicators on Eurostat, e.g.

- Number of enterprises in Sector "Manufacture of food products and beverages"

- Number of employees in Sector "Manufacture of food products and beverages"

- Value added in manufacturing in the EU-27 by sector

- Number of employees in Sector "Manufacture of food products and beverages" as Percentage of total (based on hours worked)

By analyzing these indicators, I faced several problems. (1) the most important was the lack of information. For some countries, the data were missing for a longer period or they did not exist, which made impossible to compare the data. I decided to use " 0 " in my analysis (as it can be seen in the following charts), which means: not existing data. (2) In some cases, only data from different years were available. In these cases, the charts contain the last available data. The countries with other basis years are seen in charts marked with the reference years.

Before going into deeper analysis, I have chosen 2 of the possible indicators from the above mentioned list: the number of enterprises and the number of employees in Sector "Manufacture of food products and beverages".

Regarding the number of enterprises in the Food Processing Sector, the latest data were from 2007. For 6 countries, I had to choose other reference years varied from 2001 to 2006 . By 8 countries there were no data to find. The TOP 10 countries are listed in Figure 1. in term of number of enterprises in Sector "Manufacture of food products and beverages".

Figure 1. Number of enterprises in Sector "Manufacture of food products and beverages", 2007

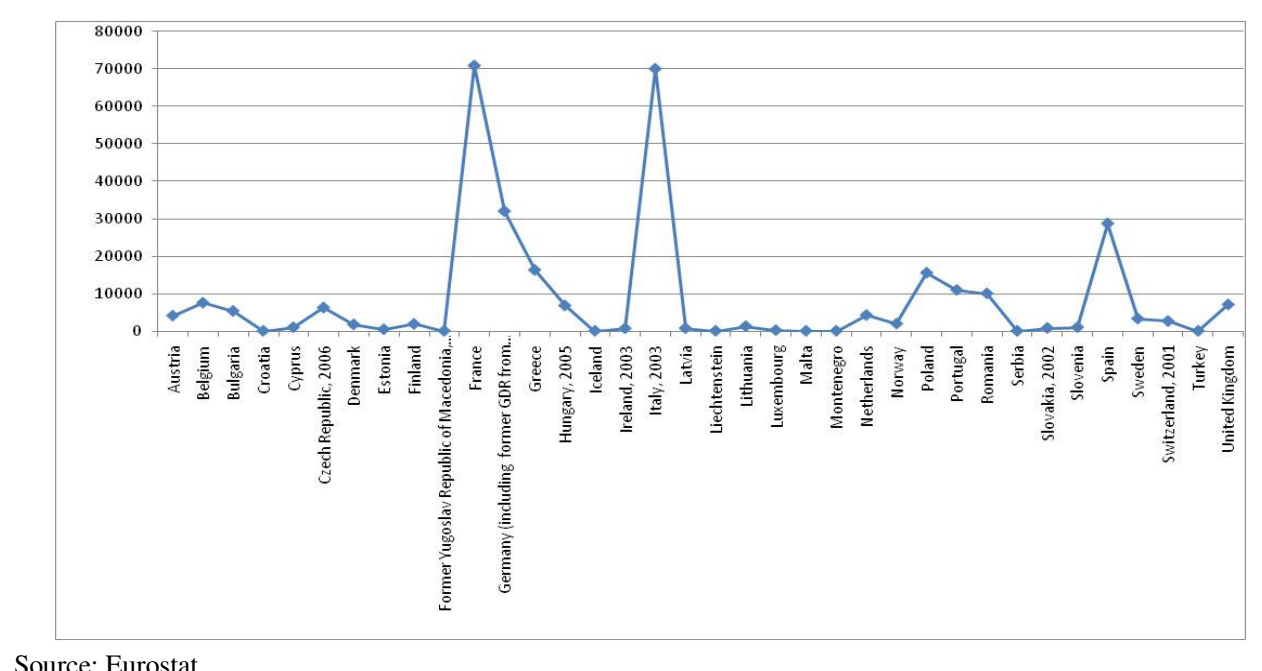

Source: Eurostat

By analyzing the number of employees of the Food Processing Sector, we can see that in the case of 11 countries, there are missing data (marked with " 0 ") and in the case of 9 countries, I had to choose another reference year than 2007. The best performing countries regarding number of empolyees in Sector "Manufacture of food products and beverages" are listed in Figure 2. 
Figure 2. Number of employees in Sector "Manufacture of food products and beverages", 2007, Eurostat

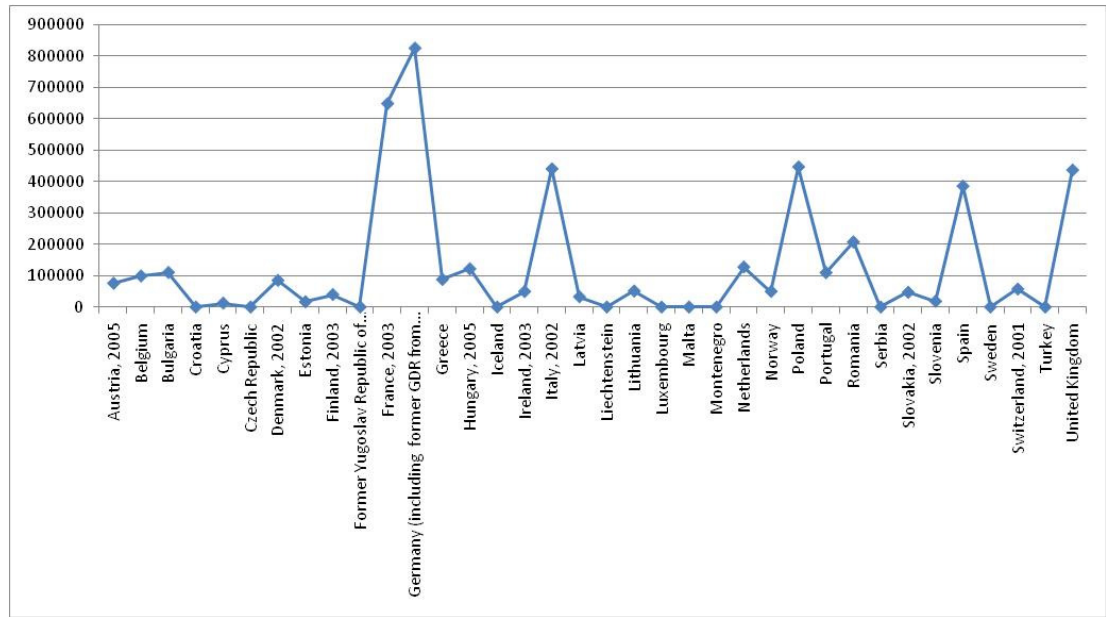

Source: Eurostat

By looking at these data, we can see a huge variaty in size of companies which can be seen from the Figure 3. which is an own calculation based on the 2 charts above. In my oppinion, it is important to see whether the number of companies in a country are SMEs or more traditional family-based companies which typical for the food industry. SMEs are rather suitable for a cluster type cooperation than micro companies.

Figure 3. Average number of empleyees per enterprises in Sector "Manufacture of food products and beverages"

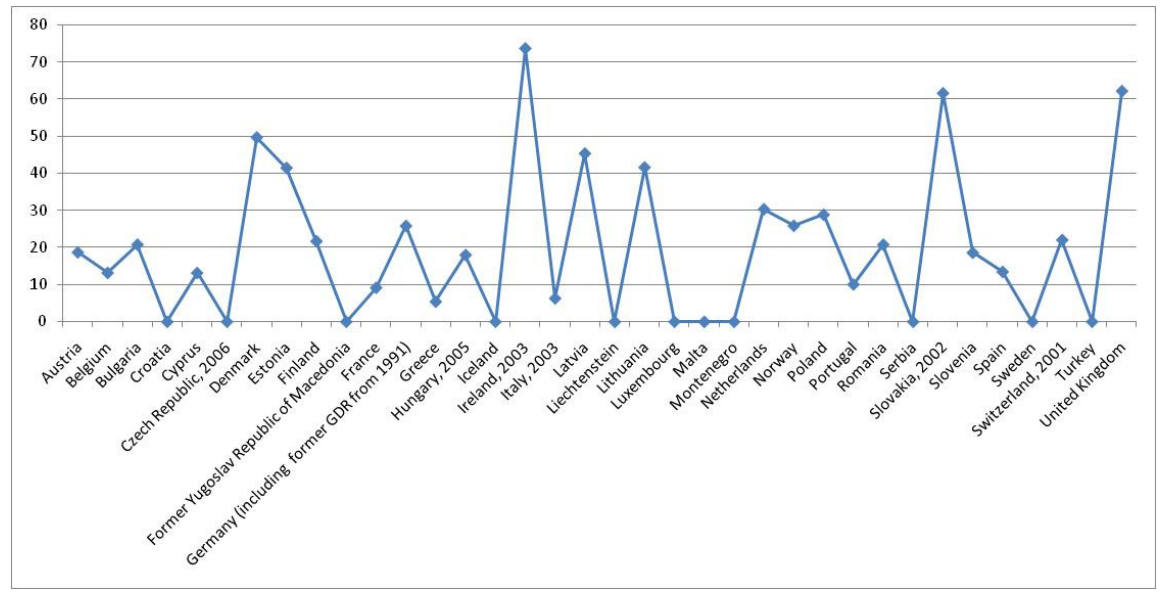

Source: Eurostat

\subsection{Formation of clusters}

In the last decades several hunders of clusters were formulated not only in Europe but over the world. Some of these clusters are formalized which means that a cluster managment organization were set up to animate the cluster activities.

The existing statistics and analysis on clusters are not holistic. There are already some European initiatives where common efforts are done to collect all clusters in the different sectors across Europe, but an EU-wide comprehensive database is still lacking.

The most important initiatives are:

- The clusterobservatory program (www.clusterobservatory.eu) which provides an online platform with information and analysis of clusters and cluster policy in Europe. The European Cluster Observatory also produces analysis and reports on regional competitiveness conditions, transnational cluster networks, clusters in emerging industries, and studies on better practices in cluster organisations.

- The European Cluster Collaboration Platform was launched last September by the European 
Commission, cluster managers and cluster experts. It aims to provide information and services for their members that enables better and more targeted interaction between cluster organisations and their members (www.cluster-collaboration.eu).

Using exclusively these databases, I could find 81 food clusters. I have prepared the following chart using these data. The countries with the most food clusters are listed in Figure 4.

Figure 4. Number of Food Clusters in Europe, 2011

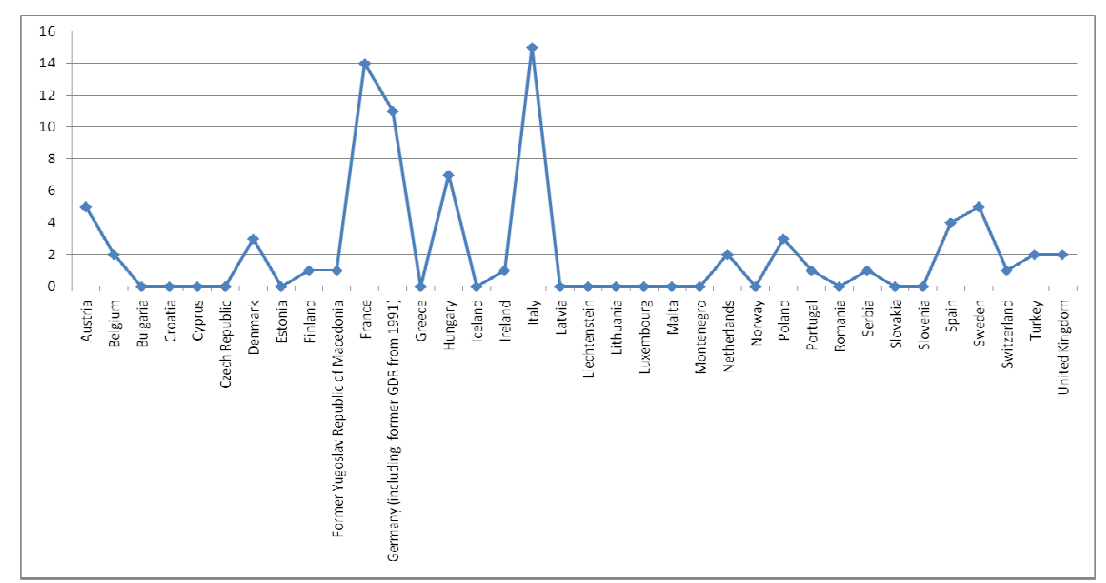

Source: Self edited based on data of www.clusterobservatory.eu and www.cluster-collaboration.eu

\section{CONCLUSION}

By looking for statistical measurable connections among the three most relevant indicators analyzed above, I have prepared a comparison table, as follows, which helps one to see the possible interdependencies among the indicators more clearly.

Table 1

Ranking of indicators

\begin{tabular}{|c|c|c|c|}
\hline Rank & $\begin{array}{c}\text { Number of food clusters in } \\
\text { Europe, 2011 }\end{array}$ & $\begin{array}{c}\text { Number of employees in Sector } \\
\text { "Manufacture of food products and } \\
\text { beverages", 2007 }\end{array}$ & $\begin{array}{c}\text { Number of enterprises in Sector } \\
\text { "Manufacture of food products } \\
\text { and beverages", 2007 }\end{array}$ \\
\hline 1 & Italy & Germany & France \\
\hline 2 & France & France & Germany \\
\hline 3 & Germany & Poland & Spain \\
\hline 4 & Hungary & Italy & Preece \\
\hline 5 & Sweden & UK & Portugal \\
\hline 6 & Austria & Spain & Romania \\
\hline 7 & Spain & Romania & Belgium \\
\hline 8 & Poland & Hungary & UK \\
\hline 9 & Denmark & Bulgaria & \\
\hline 10 & UK & & \\
\hline
\end{tabular}

Source: Self edited from Figures 1, 2 and 4

Based on these analyses, it is clear that a strong correlation exists between the indicators listed in Table 1. In most of the cases the countries are ranked at the highest level where the number of employees and number of enterprises in Sector "Manufacture of food products and beverages" are also at the highest.

Based on the Figure 3 it can be seen that there are no correlation between the average size of enterprises and the existence of clusters in the analysed sector.

It is important to remark that the correlation between the different statistical indicators and the existence of clusters in a given sectors are depending on several factors beyond them. In this anlysis, I have chosen some already existing indicators from the Eurostat database even facing some statistical problem by doing that. In my opinion, a more detailed qualitative and quantitive primery research is needed in the future.

\section{REFERENCES}

Marshall, A. (1890/1920) Principles of Economics. 8th ed. (1st ed. 1890). London: Macmillan.

Porter, M. E. (1990) The Competitive Advantage of Nations, New York: The Free Press.

Regional clusters in Europe, Observatory of European SMEs, 2002, No. 3, ISBN 92-894-3560-7 
Eurostat, www.ec.europa.eu/eurostat www.clusterobservatory.eu

www.cluster-collaboration.eu 